\title{
Which Fault Segments Ruptured in the 2008 Wenchuan Earthquake and Which Did Not? New Evidence from Near-Fault 3D Surface Displacements Derived from SAR Image Offsets
}

\author{
by Guangcai Feng, Sigurjón Jónsson, and Yann Klinger
}

\begin{abstract}
The $2008 M_{\mathrm{w}} 7.9$ Wenchuan earthquake ruptured a complex thrustfaulting system at the eastern edge of the Tibetan plateau and west of Sichuan basin. Though the earthquake has been extensively studied, several details about the earthquake, such as which fault segments were activated in the earthquake, are still not clear. This is in part due to difficult field access to the fault zone and in part due to limited near-fault observations in Interferometric Synthetic Aperture Radar (InSAR) observations because of decorrelation. In this study, we address this problem by estimating SAR image offsets that provide near-fault ground displacement information and exhibit clear displacement discontinuities across activated fault segments. We begin by reanalyzing the coseismic InSAR observations of the earthquake and then mostly eliminate the strong ionospheric signals that were plaguing previous studies by using additional postevent images. We also estimate the SAR image offsets and use their results to retrieve the full 3D coseismic surface displacement field. The coseismic deformation from the InSAR and image-offset measurements are compared with both Global Positioning System and field observations. The results indicate that our observations provide significantly better information than previous InSAR studies that were affected by ionospheric disturbances. We use the results to present details of the surface-faulting offsets along the Beichuan fault from the southwest to the northeast and find that there is an obvious right-lateral strike-slip component (as well as thrust faulting) along the southern Beichuan fault (in Yingxiu County), which was strongly underestimated in earlier studies. Based on the results, we provide new evidence to show that the Qingchuan fault was not ruptured in the 2008 Wenchuan earthquake, a topic debated in field observation studies, but show instead that surface faulting occurred on a northward extension of the Beichuan fault during or immediately following the mainshock.
\end{abstract}

Electronic Supplement: Parallel ascending-orbit track coseismic deformation.

\section{Introduction}

The $M_{\mathrm{w}} 7.9$ Wenchuan earthquake occurred on 12 May 2008 and ruptured active faults of the Longmen Shan thrust belt, which mark the boundary between the eastern margin of the Tibetan plateau and the Sichuan basin (Fig. 1). The earthquake caused extensive damage to cities and counties along the northwestern margin of the Sichuan basin, such as in Yingxiu, Beichuan, and Nanba, and resulted in the loss of tens of thousands of human lives (Shen et al., 2009). Thousands of landslides were triggered by the mainshock and large

*Now at School of Geosciences and Info-Physics, Central South University, Changsha 410083, China. aftershocks, seriously hindering rescue efforts, early field investigations, and geodetic surveying (Global Positioning System [GPS] and leveling) after the earthquake (Yin, 2010; Wang et al., 2011). This event, however, provided a rare opportunity to study the rupture features and surface deformation of great intraplate thrust earthquakes with space-based geodetic techniques, such as Interferometric Synthetic Aperture Radar (InSAR), in areas with sparse land-based geodetic observations due to limited accessibility and rugged topography.

Many aspects of the 2008 Wenchuan earthquake have already been documented, such as the surface-fault traces, rupture lengths, offsets along the faults and the related 


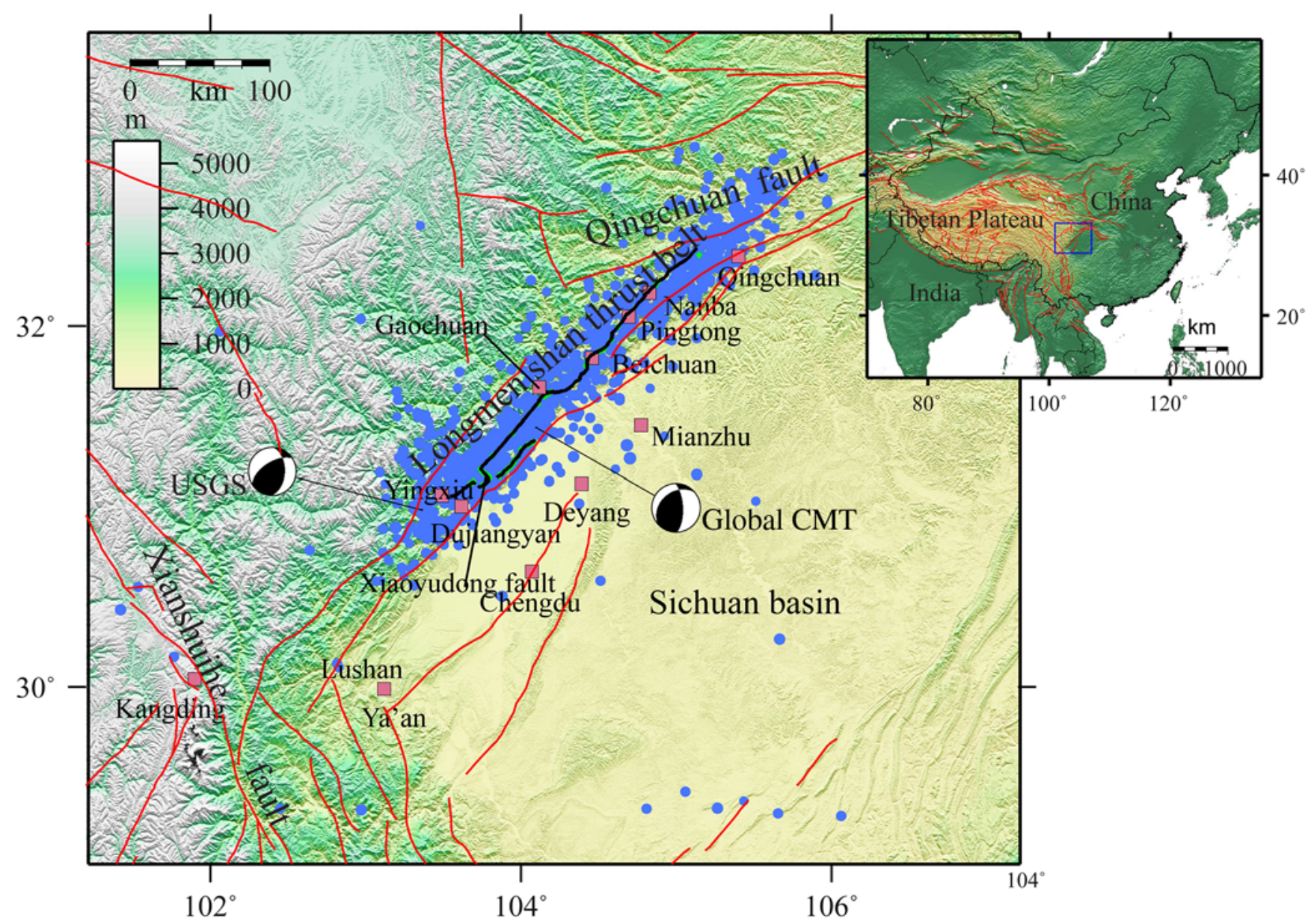

Figure 1. Map of the Wenchuan earthquake area showing mapped faults, the coseismic surface ruptures, and locations of aftershocks above magnitude 3 from the U.S. Geological Survey (USGS). The two Wenchuan focal mechanisms are from the USGS and Global Centroid Moment Tensor (CMT). The squares indicate locations of cities and the inset shows the location of the study area (rectangle) in China. The color version of this figure is available only in the electronic edition.

coseismic deformation, rupture mechanism, fault geometry, and fault-slip distribution (e.g., Klinger et al., 2010; Kurahashi and Irikura, 2010; Yin, 2010; Zhang et al., 2010, 2012; Fielding et al., 2013). The studies that report on the faulttrace location and the amount of surface-faulting offset are mainly based on either field investigations (Lin et al., 2009; Liu-Zeng et al., 2009; Xu et al., 2009; Li et al., 2010) or geodetic measurements (Hao et al., 2009; Shen et al., 2009; Feng et al., 2010; Tong et al., 2010; Wang et al., 2011; Fielding et al., 2013).

Three independent field studies measured the entire length of the earthquake fault ruptures along the Beichuan and Pengguan faults (Lin et al., 2009; Liu-Zeng et al., 2009; Xu et al., 2009). In addition, the northernmost segment (70 km long) of the Beichuan fault was studied by Li et al. (2010). Although these studies present a broadly similar pattern of fault offsets, the reported values of vertical and horizontal fault offsets differ significantly at several locations along the Beichuan fault, such as in Yingxiu, Beichuan, and Qingchuan (see Fig. 1). Remaining key questions include (1) was the Qingchuan fault, located to the northeast of the main fault ruptures, activated in the 2008 Wenchuan earthquake? Both Xu et al. (2009) and Liu-Zeng et al. (2009) reported that the mainshock only ruptured the two subparallel northwest-dipping Beichuan and Pengguan faults. However, Lin et al. $(2009,2012)$ claimed that the Qingchuan fault $(\sim 60 \mathrm{~km})$ also slipped in the earthquake based on their latest field investigation. (2) How did the slip direction vary from southwest to northeast on the Beichuan fault? Most previous studies claim that the deformation on the Beichuan fault changed systematically toward the northeast, from a dominant thrust motion to a nearly pure right-lateral slip motion on the shallow-dipping rupture plane. However, Lin et al. (2009) proposed that a left-lateral slip of up to $4.2 \mathrm{~m}$ and a reverse slip of $2.5 \mathrm{~m}$ occurred along the southern Beichuan fault. (3) What are the peak horizontal and vertical surface rupture offset values, and where are they located? The published studies also differ on this topic. The divergence of previous studies' conclusions is probably due to several factors, for example, dissimilar survey methods, different assumptions about the primary rupture plane, and different sites of observation. Furthermore, a detailed and complete record 
Table 1

Ascending Advanced Land Observing Satellite (ALOS) Data Used in This Study

\begin{tabular}{cccccrrr}
\hline & & Group A & Group B & Group C & & Perpendicular Baseline (m) \\
Track & Frame & $\begin{array}{c}\text { Date of Slave 1 } \\
\text { (yyyy/mm/dd) }\end{array}$ & $\begin{array}{c}\text { Date of Master } \\
\text { (yyyy/mm/dd) }\end{array}$ & $\begin{array}{c}\text { Date of Slave 2 } \\
\text { (yyyy/mm/dd) }\end{array}$ & Pairs BA & Pairs BC \\
\hline 471 & $600-650$ & $2008 / 02 / 29$ & $2008 / 05 / 31$ & $2010 / 09 / 06$ & & 82 & -484 \\
472 & $600-650$ & $2008 / 01 / 31$ & $2008 / 06 / 17$ & $2009 / 08 / 05$ & & 206 & -222 \\
473 & $600-650$ & $2008 / 02 / 17$ & $2008 / 05 / 19$ & $2011 / 01 / 10$ & & 203 & 45 \\
474 & $600-650$ & $2008 / 03 / 05$ & $2008 / 06 / 05$ & & & 273 & \\
475 & $600-650$ & $2007 / 06 / 20$ & $2008 / 06 / 22$ & $2009 / 09 / 25$ & & 6 & -427 \\
476 & $600-650$ & $2008 / 04 / 08$ & $2008 / 05 / 24$ & $2011 / 01 / 15$ & & -196 & 218 \\
\hline
\end{tabular}

of the coseismic surface slip variations along the surface rupture zones is still unavailable due to a combination of access difficulties (Yin, 2010), fault burial by landslides, and a fault-trace cutting slopes too steep to permit straightforward surveying. Therefore, there may be much to gain from an independent space-based observation dataset to complement and validate those field-based studies.

In addition to the above-mentioned field investigations, geodetic GPS, InSAR, and leveling measurements have been used to map the coseismic deformation of the Wenchuan earthquake and to estimate the fault slip (Hao et al., 2009; Shen et al., 2009; Feng et al., 2010; Tong et al., 2010; Wang et al., 2011). Though there are around 500 GPS (435 campaign and 38 continuous GPS) sites and triangulation sites in this region, they have an uneven distribution, with most of them located on the footwall block of the aforementioned faults and with very few GPS stations $(<50)$ located near the fault rupture (Wang et al., 2011). InSAR data are therefore of key importance for studying this earthquake. Most of the published InSAR studies of the Wenchuan earthquake used the ascending Advanced Land Observing Satellite (ALOS) data that unfortunately include strong ionospheric distortions, resulting in significantly biased coseismic deformation maps as well as dissimilar estimations of the fault-slip distribution at depth (Hao et al., 2009; Shen et al., 2009; Feng et al., 2010; Furuya et al., 2010; Hashimoto et al., 2010; Tong et al., 2010; Wang et al., 2011; Fielding et al., 2013). Although some approaches have been proposed to correct the ionospheric effects, the success has been limited (Raucoules and de Michele, 2010; Feng, 2011), and long wavelength ionospheric signals remained in the interferograms.

In addition, the InSAR observations of the 2008 Wenchuan earthquake are decorrelated near the fault ruptures, so they provide neither accurate information about the near-fault displacements (within $200 \mathrm{~m}$ of the fault ruptures) nor exactly what faults were activated. Pixel-offset tracking between two SAR images can be used to estimate large surface displacements in both the line of sight (LoS) direction and along the satellite's flying (azimuth) direction based on intensity cross correlation between small subimages (patches) in the SAR images (Strozzi et al., 2002). Pixel-offset tracking has already been used to quantify the ground displacements and to map the fault trace of the Wenchuan earthquake (Kobayashi et al., 2009; de Michele, Raucoules, Lasserre, et al., 2010). de Michele, Raucoules, de Sigoyer, et al. (2010) also tried to retrieve the 3D surface displacements of this event using additional Envisat data from the descending orbit. However, the calculated azimuth offsets used in these studies are also severely affected by ionospheric disturbances, limiting the use of the data to resolve the fault trace and resulting in errors in the 3D surface displacement inversion.

To address the problems discussed above, we here propose a simple method to reduce the effects of the ionospheric disturbances by utilizing additional postevent SAR images that do not include strong ionospheric effects. We then calculate the azimuth and range offsets with descending Envisat and ionosphere-corrected ascending ALOS datasets. Combining their range and azimuth offsets, we estimate the complete 3D surface displacements that reveal which fault segments ruptured in the earthquake. To validate our new measurements, we compare them with available GPS observations and field reports. Finally, we use our new coseismic surface displacements to address the three questions mentioned above.

\section{InSAR Observations}

\section{SAR Data Processing}

We use SAR datasets from the Japanese ALOS (wavelength $23.6 \mathrm{~cm}$ ) and European Envisat radar satellites (wavelength $5.6 \mathrm{~cm}$ ) to map the LoS coseismic deformation of this event. We also calculate image offsets with those datasets to derive 3D coseismic surface displacements in the Wenchuan earthquake rupture zone. The ALOS data consist of stripmode data acquired from six parallel ascending-orbit tracks (from paths 471 to 476, see Table 1) and Scanning synthetic aperture radar (ScanSAR) mode data acquired from a descending pass (path 124, see Table 2). In addition, we use data from two parallel Envisat descending tracks (tracks 18 and 290, see Table 2). Together the InSAR datasets provide information for a $400 \mathrm{~km} \times 400 \mathrm{~km}$ area covering the entire coseismic deformation field (see Figs. 2 and 3).

We obtained all the interferograms from strip- and ScanSAR-mode SAR data (level 1.0 for ALOS and level 0 for Envisat) by applying the standard two-pass differential InSAR method using the GAMMA SAR processing software 


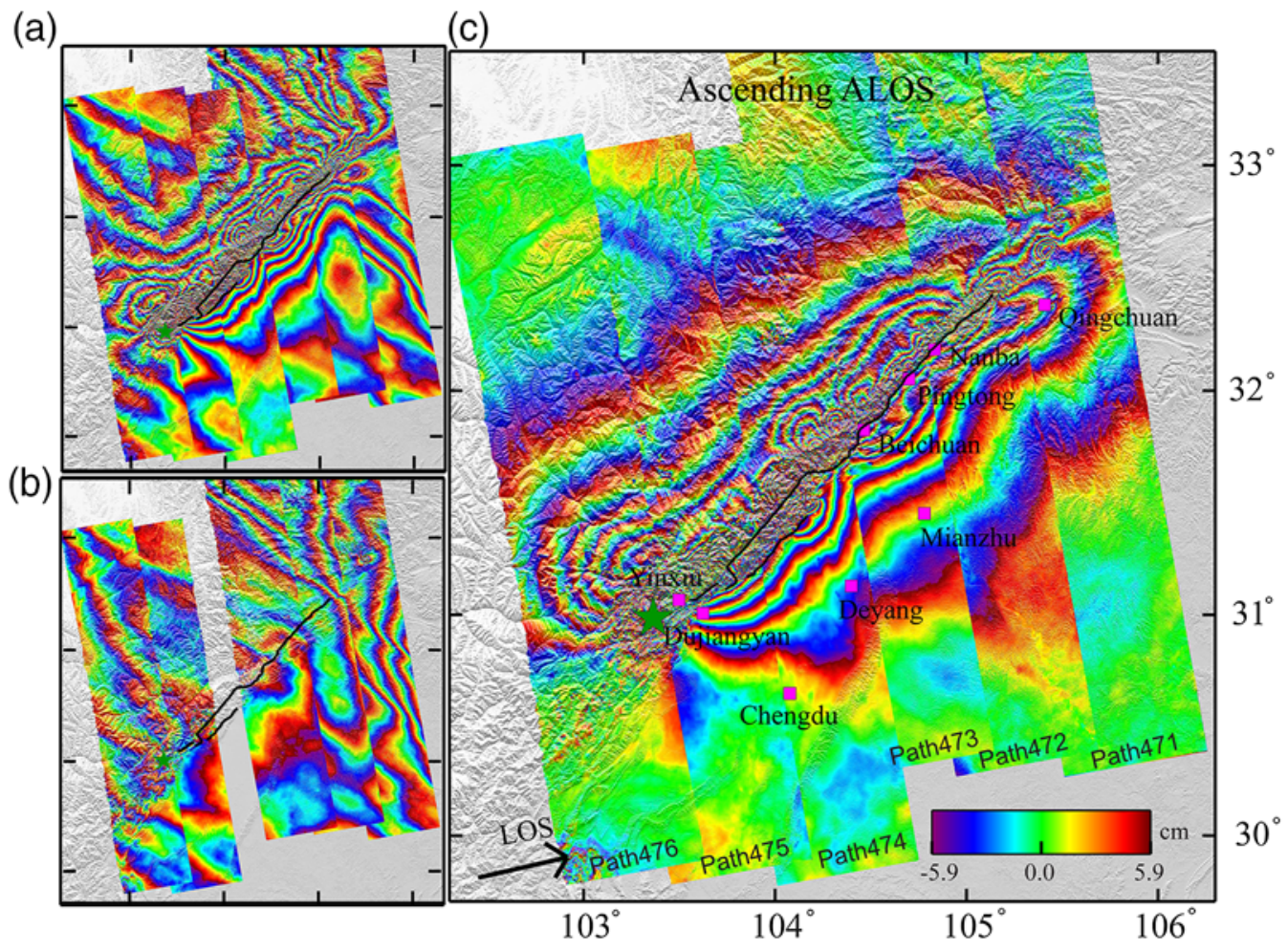

Figure 2. Ascending Advanced Land Observing Satellite (ALOS) interferograms with each fringe cycle representing $11.8 \mathrm{~cm}$ line of sight (LoS) displacement. (a) The original coseismic interferograms contaminated with ionospheric perturbations. (b) Postearthquake interferograms that only contain the ionospheric signals. (c) Corrected interferograms after removal of ionospheric fringes and phase ramps. Positive values correspond to displacement of the ground toward the LoS direction of the satellite (indicated by the arrow). The color version of this figure is available only in the electronic edition.

package (Wegmüller and Werner, 1997). We combined ALOS FBS (fine beam single polarization) data with ALOS FBD (fine beam double polarization) data by oversampling the FBD data to a similar pixel spacing as the FBS data. To remove topographic signals in the interferograms, we used the 90-m Shuttle Radar Topography Mission v.4.1 digital elevation model $(\mathrm{DEM})$ and then applied multilooking $(6 \times 16$, $3 \times 16$, and $4 \times 20$ for the ALOS, ALOS ScanSAR, and Envisat data, respectively, in the range and azimuth directions) before phase unwrapping. The interferograms were smoothed with an improved Goldstein filter (Li et al., 2008) and unwrapped using a minimum-cost-flow algorithm, which minimizes phase-jump errors and simultaneously maximizes the availability of InSAR phases (Chen and Zebker, 2001).

For the ALOS paths 473-475, the fault rupture causes a zone of signal decorrelation that prevents phase unwrapping

\section{Table 2}

Descending ALOS Scanning Synthetic Aperture Radar (ScanSAR) and Envisat Data Used in This Study

\begin{tabular}{ccccc}
\hline Track & Mode & $\begin{array}{c}\text { Date of Master } \\
\text { (yyyy/mm/dd) }\end{array}$ & $\begin{array}{c}\text { Date of Slave } \\
(\text { yyyy/mm/dd) }\end{array}$ & $\begin{array}{c}\text { Perpendicular } \\
\text { Baseline }(\mathrm{m})\end{array}$ \\
\hline 18 & IS2 & $2006 / 02 / 08$ & $2008 / 09 / 10$ & 121 \\
290 & IS2 & $2008 / 03 / 03$ & $2008 / 06 / 16$ & 488 \\
124 & WB1 & $2008 / 01 / 31$ & $2008 / 05 / 20$ & 798 \\
\hline
\end{tabular}

across the fault. It was therefore necessary to carry out the phase unwrapping separately on the two parts and then to calibrate the phase ambiguity across the fault ruptures. Such calibration can be done with external data (e.g., GPS observations) or with reference points far from the fault ruptures, where surface deformation is assumed to be negligible (Feng, Li, et al., 2015; Feng, Zhiwei, et al., 2015). We choose the latter option. Finally, interferograms from adjacent tracks were adjusted and combined into a common reference based on GPS data far away from the earthquake rupture (Wang et al., 2011).

Coseismic Interferograms and Ionospheric Effects Correction

The coseismic deformation of the 2008 Wenchuan earthquake obtained by previous studies (e.g., Hao et al., 2009; Shen et al., 2009) shows multiple deformation fringes near the earthquake ruptures and also exhibits significant longwavelength errors far away the fault ruptures (see Fig. 2a). Earlier studies showed that these errors are mainly due to ionospheric disturbances (Feng et al., 2010; Tong et al., 2010; Feng, 2011; Wang et al., 2011) and that their magnitude can be up to $\sim 0.5 \mathrm{~m}$ in the InSAR observations and more than $10 \mathrm{~m}$ ( $\sim 3$ pixels $)$ in the azimuth offset measurements (Kobayashi et al., 2009; Shen et al., 2009; Feng, 


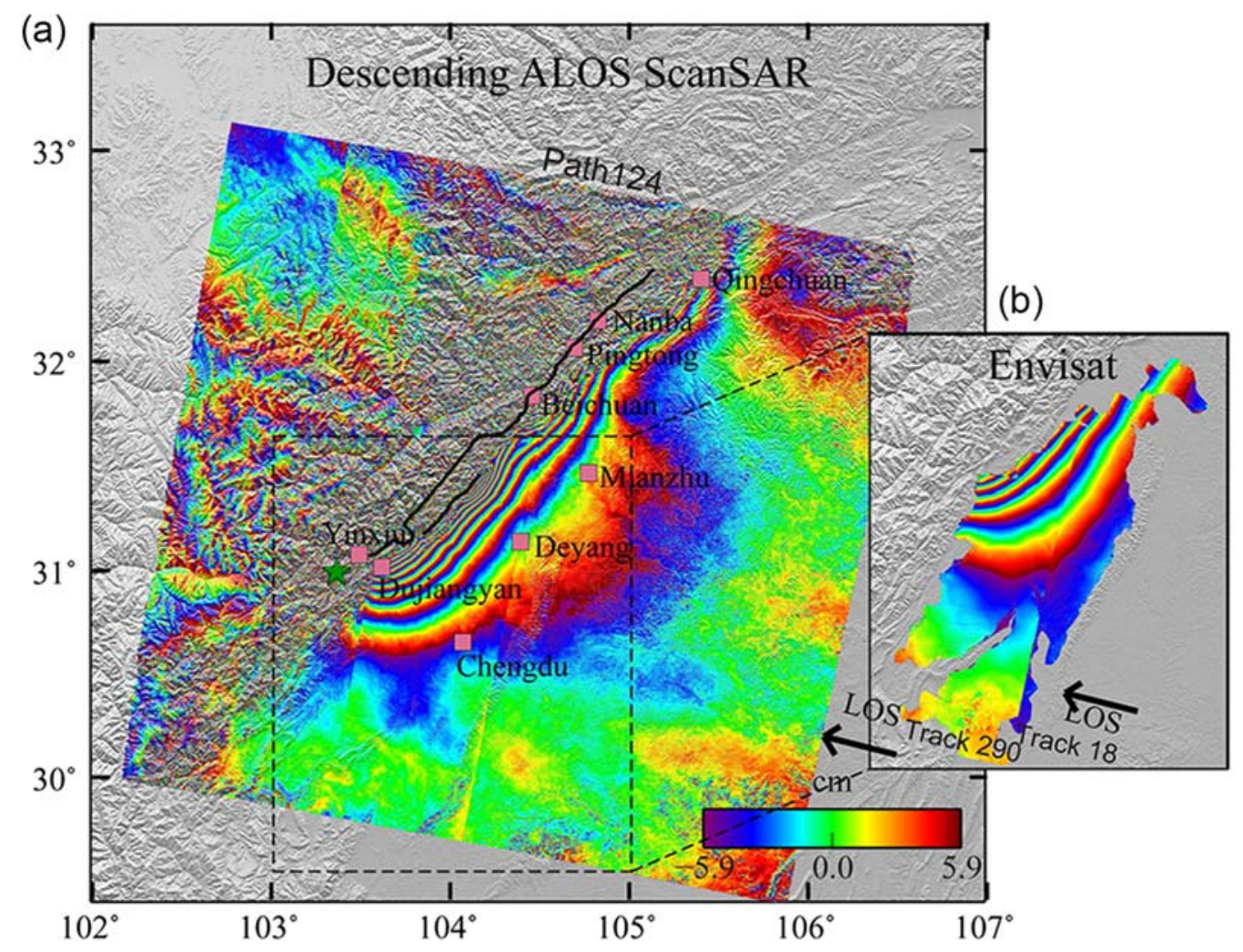

Figure 3. Descending coseismic interferograms from (a) ALOS Scanning synthetic aperture radar (ScanSAR) and (b) Envisat data. Both interferograms are displayed using $11.8 \mathrm{~cm}$ per fringe and with positive values corresponding to ground displacement toward the LoS direction of the satellites (indicated by the arrows). The color version of this figure is available only in the electronic edition.

2011). Though these errors have been dealt with by different methods (Wegmüller et al., 2006; de Michele, Raucoules, Lasserre, et al., 2010), they are still hard to correct because ionospheric signals, such as atmospheric delays, are completely dependent on SAR acquisition time. Using the pixel-offset tracking technique, ionospheric effects in ALOS images can easily be identified (Wegmüller et al., 2006). Our tests show that all of the postearthquake acquisitions (group B in Table 1), except the one from path 474 (see Fig. 2), were contaminated by strong ionospheric disturbances (Feng, 2011). Earlier experiments showed that the SAR images acquired near local midnight are more commonly affected by ionospheric disturbances (Chapin et al., 2006; Feng, 2011).

To address this problem, we isolated the ionospheric effects in the ALOS data by generating two sets of interferograms. The first set of interferograms was formed using images from before (group A in Table 1) and after (group B in Table 1) the earthquake, and these interferograms are contaminated by ionospheric disturbances (Fig. 2a). The second set of interferograms was then formed using the same postearthquake images (group B in Table 1) and postearthquake images (group $\mathrm{C}$ in Table 1) from a later date (Fig. 2b). We use the second set of interferograms, which only include the ionospheric effects (and possibly some postseismic deformation), to correct the ionospheric signals by adding the two sets of interferograms (Fig. 2c). Most ALOS images acquired during the first two years following the mainshock contain strong ionospheric effects in the rupture area (Feng, 2011), and we thus considered both the spatial baseline and amount of ionospheric disturbances when choosing the suitable postearthquake acquisitions (group $\mathrm{C}$ in Table 1). Those images were acquired within 1 or 2 years after the early postseismic images containing the strong ionospheric signals (group B in Table 1). Adding the two sets of interferograms yielded better results with less decorrelation than forming a single set of large temporal baseline interferograms (i.e., between groups $A$ and $\mathrm{C}$ in Table 1). The corrected InSAR observations exhibit much reduced ionospheric disturbances and provide more accurate coseismic interferograms (Fig. 2). The improved ALOS coseismic deformation observations of the 2008 Wenchuan earthquake can be obtained in the (E) electronic supplement.

In addition to the ascending ALOS dataset, we mapped the coseismic deformation using the descending ALOS ScanSAR and Envisat datasets. Because of the long spatial baseline (798 $\mathrm{m}$ ) of the ALOS ScanSAR data and the shorter wavelength of the Envisat satellite, we could only retrieve reliable phase observations on the footwall block (see Table 2 and Fig. 3). The resulting ascending (Fig. 2) and descending (Fig. 3) interferograms are dissimilar due to the different viewing geometry, but both are decorrelated near the Beichuan, Pengguan, and Xiaoyudong faults. The peak LoS displacements 
(a)

(b)

(c)

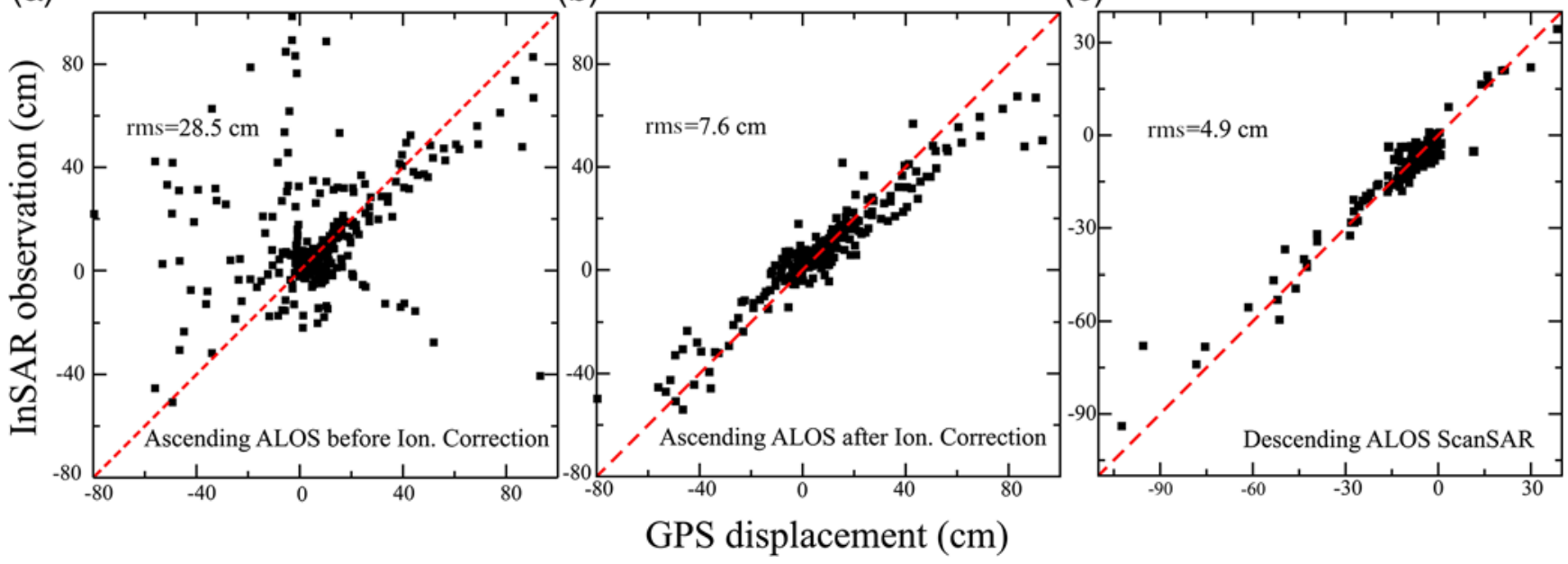

Figure 4. Comparison between Interferometric Synthetic Aperture Radar (InSAR) and Global Positioning System (GPS) observations in the LoS direction. (a,b) The correlation between ALOS InSAR and GPS observations before and after the ionospheric effect correction. (c) The correlation between the ALOS ScanSAR and GPS observations. Not all the GPS stations are included in this comparison, because some are located in areas where the InSAR observations are decorrelated. The color version of this figure is available only in the electronic edition.

in the ascending data are about $-120 \mathrm{~cm}$ on the hanging wall and $80 \mathrm{~cm}$ on the footwall, whereas in the descending data they are about $80 \mathrm{~cm}$ and $-50 \mathrm{~cm}$, respectively.

\section{Comparison to GPS}

To validate our coseismic deformation observations, we compare the InSAR observations with GPS data published in the previous studies (Shen et al., 2009; Wang et al., 2011). The GPS data consist of 435 campaign GPS and triangulation sites (resurveyed with GPS after the earthquake) and 38 continuous GPS sites. Most of the GPS surveys were finished within the first two months after the earthquake. The InSAR observations can be compared with the GPS data by projecting the GPS data into the radar LoS direction. Even though the data from the triangulation sites include key information near the fault rupture, they have large uncertainties (up to $50 \mathrm{~cm}$ ), include only 2D horizontal displacements, and are mostly located in areas where the interferograms are decorrelated. Therefore, we only use the campaign and continuous GPS data for this comparison.

The root mean square (rms) differences between the GPS on one hand and the ascending ALOS and descending ALOS ScanSAR interferograms on the other hand are 7.6 and $4.9 \mathrm{~cm}$, respectively. The ALOS ScanSAR data only cover the footwall-side of the rupture, which explains their lower rms value. The ionospheric correction greatly reduces the rms value of the ascending ALOS observations from 28.5 to $7.6 \mathrm{~cm}$, demonstrating the success of this correction. Those local differences between the InSAR and GPS observations are probably due to atmospheric delays, phase unwrapping errors, unmodeled phase ramps, and errors in the GPS observations. Furthermore, we find that the poorest agreement between the corrected ALOS and GPS observations is close to the fault rupture. When the two observations are plotted against each other (Fig. 4), the InSAR observations seem to be systematically smaller than the GPS displacements. The most likely explanation for this is that the InSAR observations are oversmoothed during the filtering process compared with GPS data. Deformation associated with postseismic processes and large aftershocks may also contribute to the differences, because most of GPS data surveys were finished within two months after the earthquake, whereas the InSAR observations include more than one or two years of postseismic deformation.

\section{SAR Image Offsets and 3D Surface Displacements}

\section{Range and Azimuth Offsets}

To complement InSAR measurements that often are decorrelated near-fault ruptures, range and azimuth pixel offsets of SAR images have been used to provide near-fault information (Michel et al., 1999; Strozzi et al., 2002; Wang and Jónsson, 2015). Like the interferograms, the azimuth offsets calculated from the ALOS images contaminated by ionospheric disturbances would also be distorted (Wegmüller et al., 2006). In most of the previous studies on the 2008 Wenchuan earthquake, pixel-offset data were therefore omitted or used cautiously in modeling due to these effects (Hao et al., 2009; Shen et al., 2009; Feng et al., 2010; Tong et al., 2010; Wang et al., 2011). The range offsets, on the other hand, are not obviously affected by the ionospheric distortions because the ionospheric phase propagation delays are on the order of the radar wavelength and represent a very small fraction of the radar range pixel size.

Because the pixel-offset tracking technique is mostly insensitive to spatial baseline, we use the ionospheric free acquisitions from groups $\mathrm{A}$ and $\mathrm{C}$ (see Table 1) to calculate the image offsets directly. After coregistering the two single look complex images acquired before and after the mainshock, 

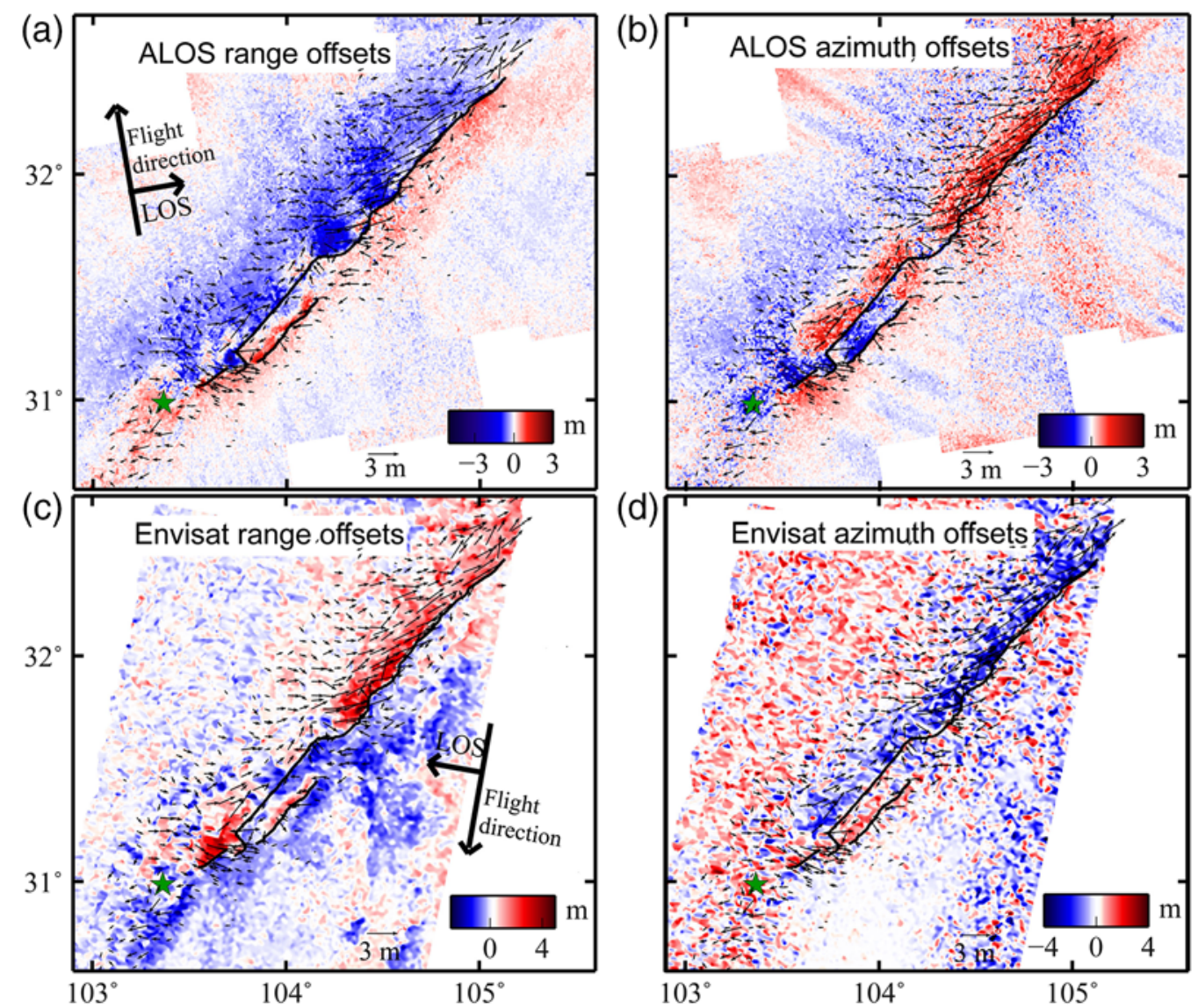

Figure 5. Pixel offsets estimated from ascending ALOS and descending Envisat data: (a) ALOS range offsets, (b) ALOS azimuth offsets, (c) Envisat range offsets, and (d) Envisat azimuth offsets. The lines show the surface-fault ruptures detected by tracing the large discontinuities in the offset maps. Positive offset values indicate horizontal ground displacements parallel to the flight direction (for azimuth offsets) or into the LoS direction toward the satellites (for range offsets). Small black arrows show derived horizontal displacements. The color version of this figure is available only in the electronic edition.

we divided the single-look SAR images into many subimages (patches) and calculated the offsets between the corresponding patches using a standard pixel-tracking procedure (Strozzi et al., 2002). We estimated the offset fields using almost square search patches of $64 \times 192$ pixels (range $\times$ azimuth) for the ALOS images (about $600 \mathrm{~m} \times 600 \mathrm{~m}$ windows) and of $64 \times 256$ pixels for the Envisat images (about $1200 \times$ $1000 \mathrm{~m}$ windows). To maintain a similar pixel spacing of around $50 \mathrm{~m}$ for the two datasets, the offsets were estimated for every 6 range and 16 azimuth pixels in the ALOS data, and for every 3 range and 15 azimuth pixels in the Envisat data. Because of the low spatial resolution of the ALOS ScanSAR images, we did not use their pixel offsets. Besides the actual coseismic surface displacement, the range offsets also include geometrical offsets in rugged terrain areas, which can be removed by the assistance of a DEM. To reduce the noise further, a $16 \times 16$ window (about $800 \mathrm{~m} \times 800 \mathrm{~m}$ ) median filter was also used. Figure 5 shows the final range and azimuth offset measurement results.

The on-ground resolution in the azimuth direction (along track) is about $3 \mathrm{~m}$ for the ALOS FBS images and about $4 \mathrm{~m}$ for the Envisat images and in the range direction (across track) about 10 and $20 \mathrm{~m}$, respectively (after projecting the slant range to ground range). When image offsets are estimated to about $1 / 32$ pixel (usually not better than $1 /$ 20 ), this corresponds to about 10 and $12.5 \mathrm{~cm}$ accuracy in the azimuth direction and about 30 and $60 \mathrm{~cm}$ accuracy in the range direction (Werner et al., 2005). The resulting ALOS image offsets are less noisy than those from Envisat (Fig. 5) because both the range and azimuth resolution of ALOS is better than that of Envisat. Furthermore, the ALOS images are also less affected by steep slopes due to the higher incidence angle of $\sim 38^{\circ}$ (compared to $23^{\circ}$ for Envisat). This is especially important in the central part of Longmen Shan where many slopes exceed $30^{\circ}$.

Although the image offsets are much noisier than the conventional InSAR observations, they can provide unambiguous range and azimuth displacements parallel and perpendicular to the LoS displacements. More importantly, the image offsets can provide displacement information close to the fault trace, where InSAR observations are not available due to decorrelation. We therefore use discontinuities in the image offset maps to locate the surface ruptures (Fig. 5) and then compare the results with field observations. 


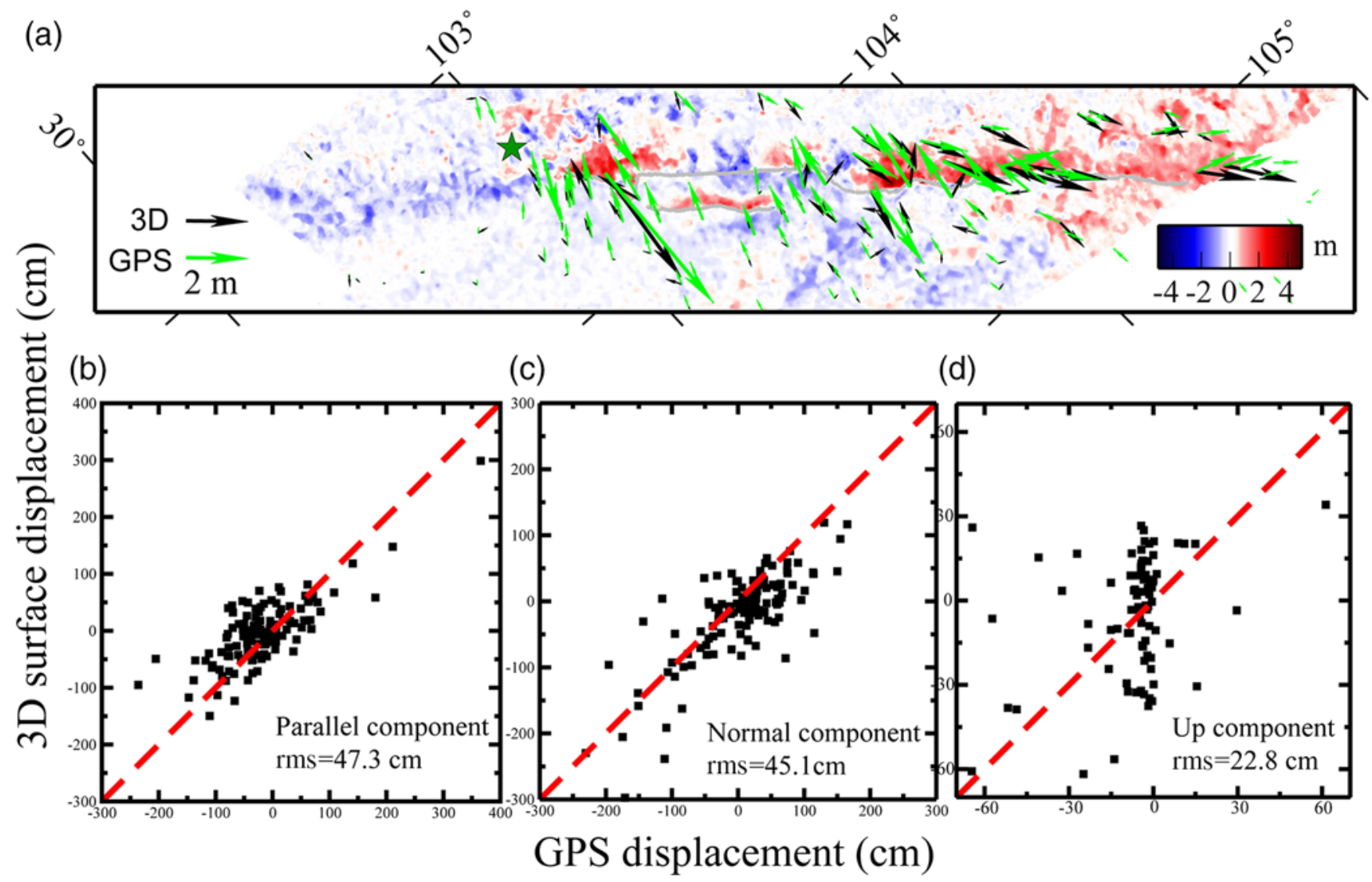

Figure 6. Comparison between the offset-derived 3D surface displacements and GPS data. This comparison includes all the GPS data because the pixel-offset tracking can provide measurements where the InSAR observations are decorrelated. The background of (a) is the vertical component of the estimated 3D surface displacement. The color version of this figure is available only in the electronic edition.

\section{D Surface Displacements}

We combined the four different image offsets (shown in Fig. 5) and used a weighted least-squares inversion to derive 3D coseismic surface displacements near the fault ruptures. The spatial resolution of ALOS is approximately two times better than that of Envisat in both the azimuth and range directions. Therefore, we accordingly gave the azimuth and range offsets of the ALOS twice the weight in the inversion. To simplify the calculation, we use average LoS unit vectors instead of the full variable unit vectors (see Table 3). The rms differences between the GPS data and the derived 3D surface displacements are $47.3,45.1$, and $22.8 \mathrm{~cm}$ for the fault parallel, normal, and up components, respectively (Fig. 6). The comparison shows that the derived $3 \mathrm{D}$ displacements are in a

Table 3

Information about the Data Used for the 3D Surface Displacement Inversion

\begin{tabular}{lccl}
\hline \multicolumn{1}{c}{ Dataset } & Satellite & Uncertainty $(\mathrm{m})$ & \multicolumn{1}{c}{ Unit Vector } \\
\hline Ascending range & ALOS & 0.2 & {$[-0.61 /-0.11 / 0.781]$} \\
Ascending azimuth & ALOS & 0.2 & {$[-0.217 /-0.976 / 0]$} \\
Descending range & Envisat & 0.4 & {$[0.346 /-0.077 / 0.934]$} \\
Descending azimuth & Envisat & 0.4 & {$[-0.217 /-0.976 / 0]$} \\
& & & \\
\hline
\end{tabular}

general agreement with the GPS measurements and that the rms values are consistent with the uncertainty of the pixeloffset measurement. However, some systematic differences are evident with the horizontal components, which are somewhat smaller in the 3D displacement derivation when compared with the GPS observations, whereas the vertical displacements appear generally larger (see Fig. 6). This deviation could be partly due to the resolution difference, with the 3D results estimated using a window size of $\sim 800 \mathrm{~m}$, whereas the GPS data are point measurements. Large landslides and aftershocks around Yingxiu, Beichuan, and Qingchuan could also contribute to differences between those two measurements in some areas (Huang and Fan, 2013).

In Figure 7, the derived 3D surface displacements are displayed as fault-parallel, fault-normal, and vertical displacements, using the average fault strike of $\mathrm{N} 219^{\circ} \mathrm{E}$. The results clearly show displacement discontinuities across the faults that were activated during the earthquake, with all displacement components exceeding several meters at many locations. In particular, the fault-parallel displacements are stronger across the northeastern half of the coseismic ruptures, whereas the fault-normal displacements appear more dominant on the middle and southern sections of the fault system. Displacement profiles across the main fault strands can provide better information about the surface-fault offsets 


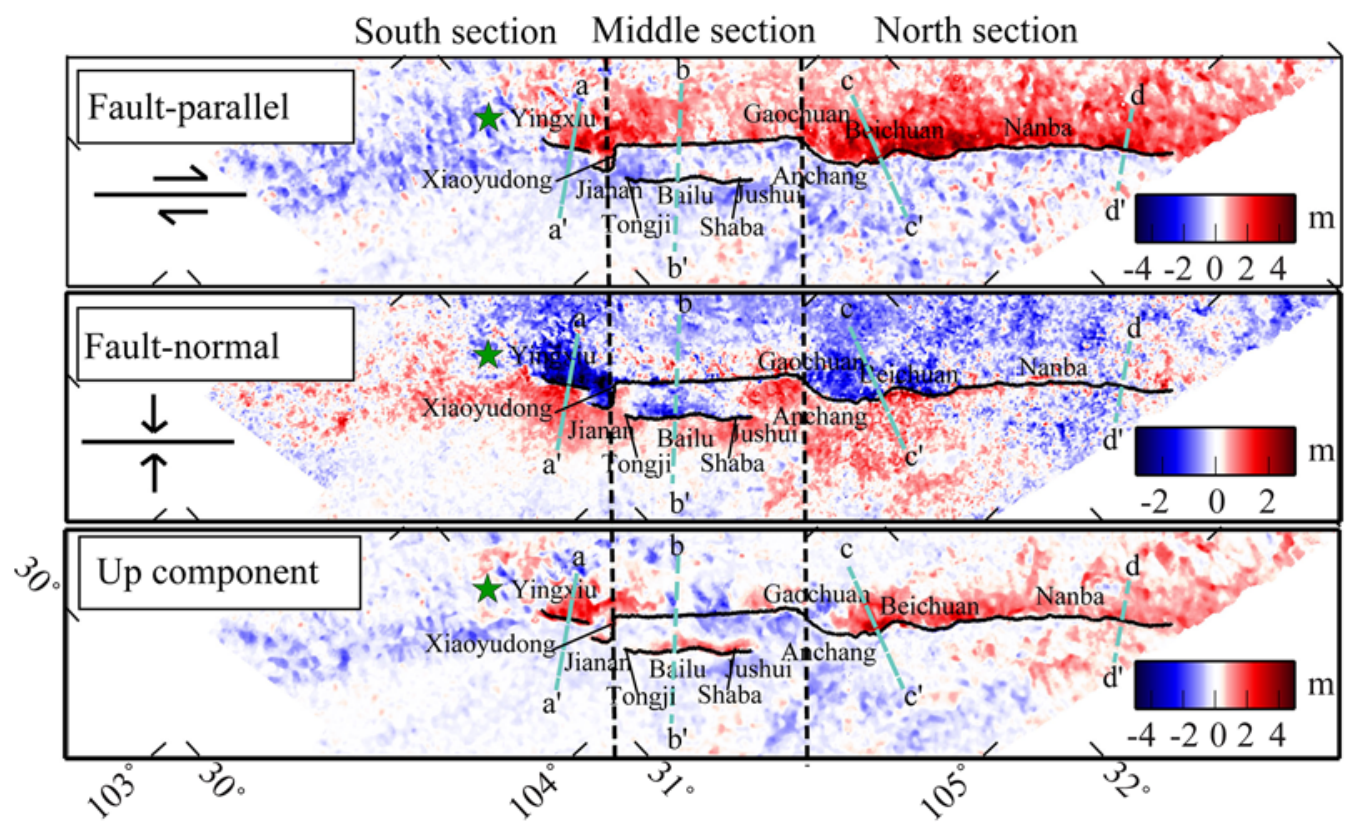

Figure 7. The derived 3D surface displacements (from the offset data in Fig. 5) shown as fault-parallel, fault-normal, and vertical displacements $($ positive $=$ right lateral/up, negative $=$ left lateral/down). Displacements along profiles a-d are shown in Figure 8. The color version of this figure is available only in the electronic edition.

(a)

(b)
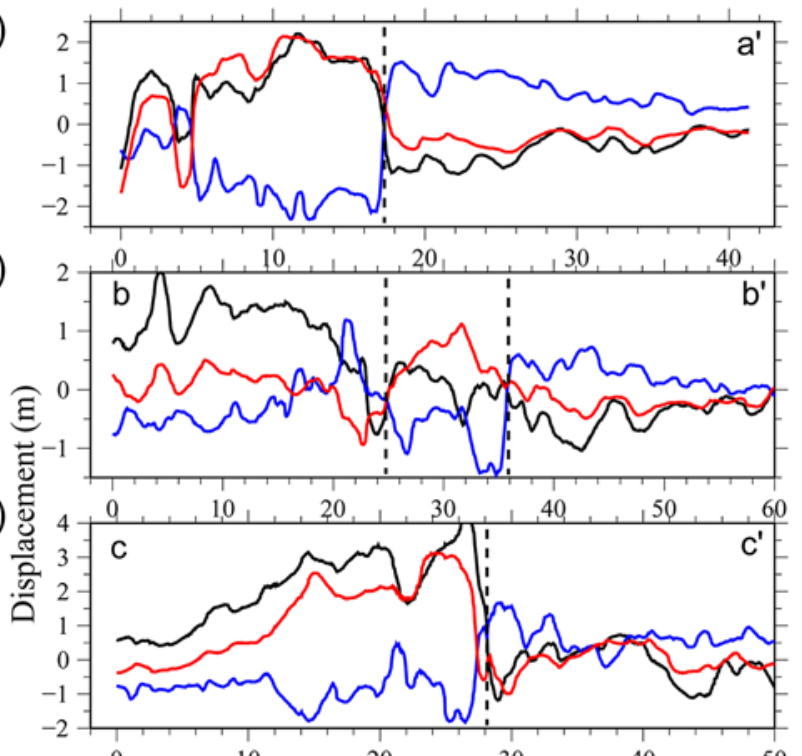

(d)

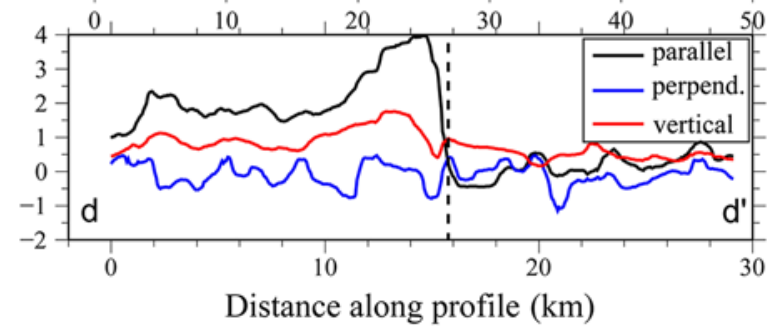

Figure 8. The fault-parallel, fault-normal, and vertical surface displacements along profiles crossing the Beichuan fault at four different locations (see Fig. 7). The sign of the displacements is the same as in Figure 7. The vertical dashed lines indicate the location of the Beichuan and Pengguan faults. The color version of this figure is available only in the electronic edition. and about the sense of motion (Fig. 8). We find that both Yingxiu and Beichuan have large right-lateral, vertical, and fault-normal displacement components, with a maximum vertical displacement of up to $6 \mathrm{~m}$ in Beichuan County. Between Xiaoyudong and Gaochuan, the Beichuan fault shows mainly right-lateral motion, whereas fault-normal and vertical displacements dominate the Pengguan fault (Figs. 7 and 8). Further north, the Nanba section mainly exhibits right-lateral displacements (around rake $55^{\circ}$ ) along with some vertical motion that decreases toward the north, whereas the motion perpendicular to the fault is small. This indicates that the fault dip progressively becomes more vertical toward the north.

\section{Comparison of the Results with Field Studies}

From the 3D displacements, we extracted the surfacefault offsets along the rupture zone and compared them with field observations (Lin et al., 2009; Liu-Zeng et al., 2009; Xu et al., 2009). We obtained the vertical offsets directly from the estimated vertical component of the $3 \mathrm{D}$ displacement field (Fig. 6c) by comparing median-averaged $1 \mathrm{~km} \times 1 \mathrm{~km}$ blocks on each side of the fault for every kilometer. Using the same method, we also estimated the horizontal (both fault-parallel and perpendicular) surface-fault offsets from the east and north components of the 3D displacement field. The horizontal surface offsets were then projected to the average strike direction of $\mathrm{N} 219^{\circ} \mathrm{E}$. Our estimated horizontal fault offsets along both the Beichuan and Pengguan faults are significantly noisier than our vertical offsets (Figs. 9 and 10). Likely reasons for this difference are the better sensitivity of the 3D displacement field to vertical displacements and noisier azimuth offsets than range offsets. The constant average strike of $\mathrm{N} 219^{\circ} \mathrm{E}$ used 
(a)

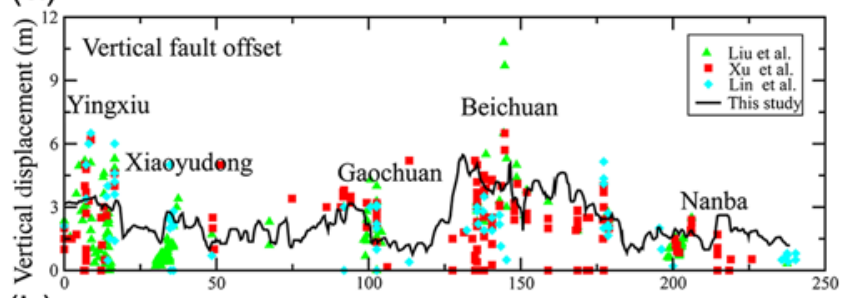

(b)

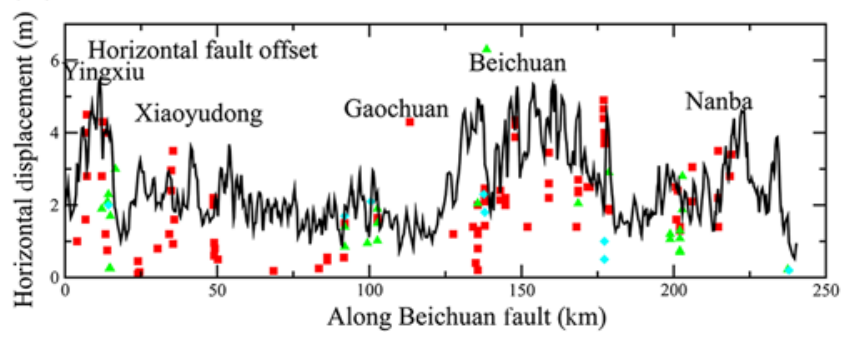

Figure 9. (a) Vertical and (b) horizontal fault offsets along the Beichuan fault as estimated from our 3D displacement derivation in comparison with the different field investigations (Lin et al., 2009; Liu-Zeng et al., 2009; Xu et al., 2009). The color version of this figure is available only in the electronic edition.

to project the horizontal fault offsets also leads to some biases in areas with large strike variations (such as Xiaoyudong and Gaochuan), although the influence is limited for the fault system as a whole.

Along the Beichuan fault, both the vertical and rightlateral fault offsets increase sharply from about $2-3 \mathrm{~m}$ in the southwest around Yingxiu and Gaochuan to about 4-5 $\mathrm{m}$ in the Beichuan County (Fig. 9). Further northeast, the fault offsets gradually decrease, with another smaller offset peak near Nanba, until they fall to zero near the Qingchuan fault. The offset values measured in the field along the Beichuan fault are generally similar or lower than what we derived in the 3D displacement estimation, though the maximum vertical and horizontal offsets measured in the field are larger (Fig. 9). The estimated vertical offsets across the Pengguan fault are much larger than the horizontal offsets, ranging from about $1 \mathrm{~m}$ in the southwest to almost $4 \mathrm{~m}$ near Shaba (Fig. 10). The estimated horizontal offsets, on the other hand, are generally between 0 and $1 \mathrm{~m}$. The offsets measured in the field also show larger vertical offsets, but the results vary widely between 0 and $3.5 \mathrm{~m}$ along the entire Pengguan fault. There are two notable differences between our results and the field studies: (1) we only observe fault offsets along the Pengguan fault between Jianan and Jushui but do not find the rupture continuing to Anchang (see Fig. 6), which contrasts the result of Liu-Zeng et al. (2009), and (2) we did not find any leftlateral offsets on the southwestern Beichuan fault, as was reported by Lin et al. (2009).

On average, coseismic offsets along strike determined in the field are either in the same range, or smaller than the offsets we estimated. In the case of smaller field offsets, this is most likely due to the absence of, or difficulty in recognizing,

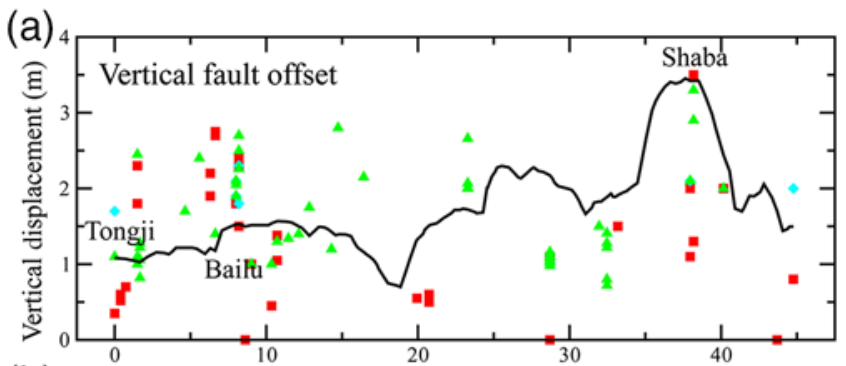

(b)

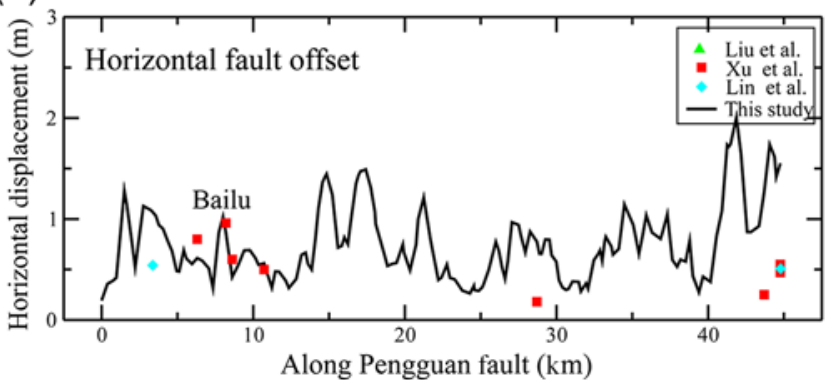

Figure 10. Same as Figure 9, except for the Pengguan fault. The color version of this figure is available only in the electronic edition.

markers that encompass the entire zone of deformation. Conversely, our measurements do integrate the deformation over the entire fault zone. In a few cases, the reported fieldderived offsets appear to be larger than our measurements. For example, in Beichuan, the field-derived vertical offsets range from 0 to $11 \mathrm{~m}$, whereas our results are consistently between 3 and $6 \mathrm{~m}$ (Fig. 9a). Similarly, vertical field-offsets for the southern part of the Pengguan fault range between 0 and $3 \mathrm{~m}$ (Xu et al., 2009), whereas we find them to be stable between 1.0 and $1.5 \mathrm{~m}$ (Fig. 10a). We suggest that such differences are probably due to the difficulties that might arise in the field in locally differentiating between the last coseismic offset and cumulative deformation. In addition, in the case of vertical deformation, one cannot rule out that some secondary landslides were misinterpreted as primary earthquake ruptures, leading to values much larger than the actual values revealed by our measurements.

We can use the derived 3D surface-fault displacements to study the ratio of horizontal and vertical offsets along the Beichuan fault (Fig. 11). We find that the ratio is around 1 for most of the rupture but has an increasing trend toward 2 along the northernmost part of the fault rupture zone. This shows that the proportion of right-lateral fault slip along the Beichuan fault increased toward the northeast, as reported by several studies already (e.g., Liu-Zeng et al., 2009; Xu et al., 2009; Zhang et al., 2012).

Contrary to most of the studies on the 2008 Wenchuan earthquake (Liu-Zeng et al., 2009; Xu et al., 2009; Yin, 2010; Zhang et al., 2010), Lin et al. (2009, 2012) proposed (based on two field surveys) that the Qingchuan fault (see Fig. 1) was activated in the earthquake with a dextral strike slip of $30-60 \mathrm{~cm}$ and a vertical displacement of $20-50 \mathrm{~cm}$. 


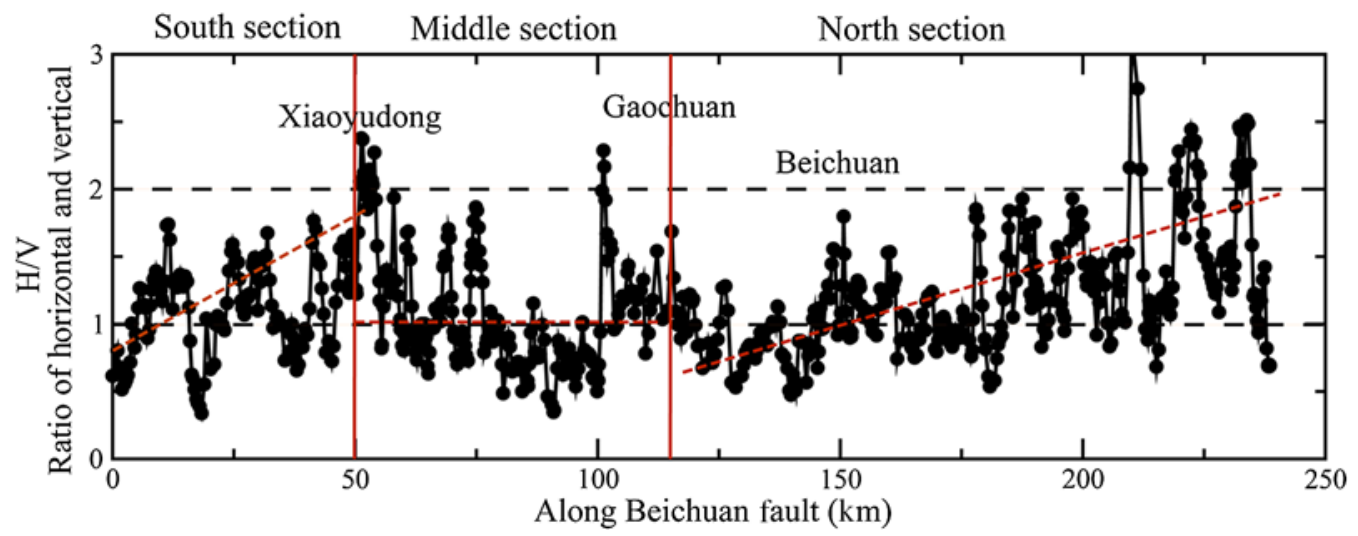

Figure 11. Ratios of horizontal and vertical fault offsets along the Beichuan fault. The color version of this figure is available only in the electronic edition.
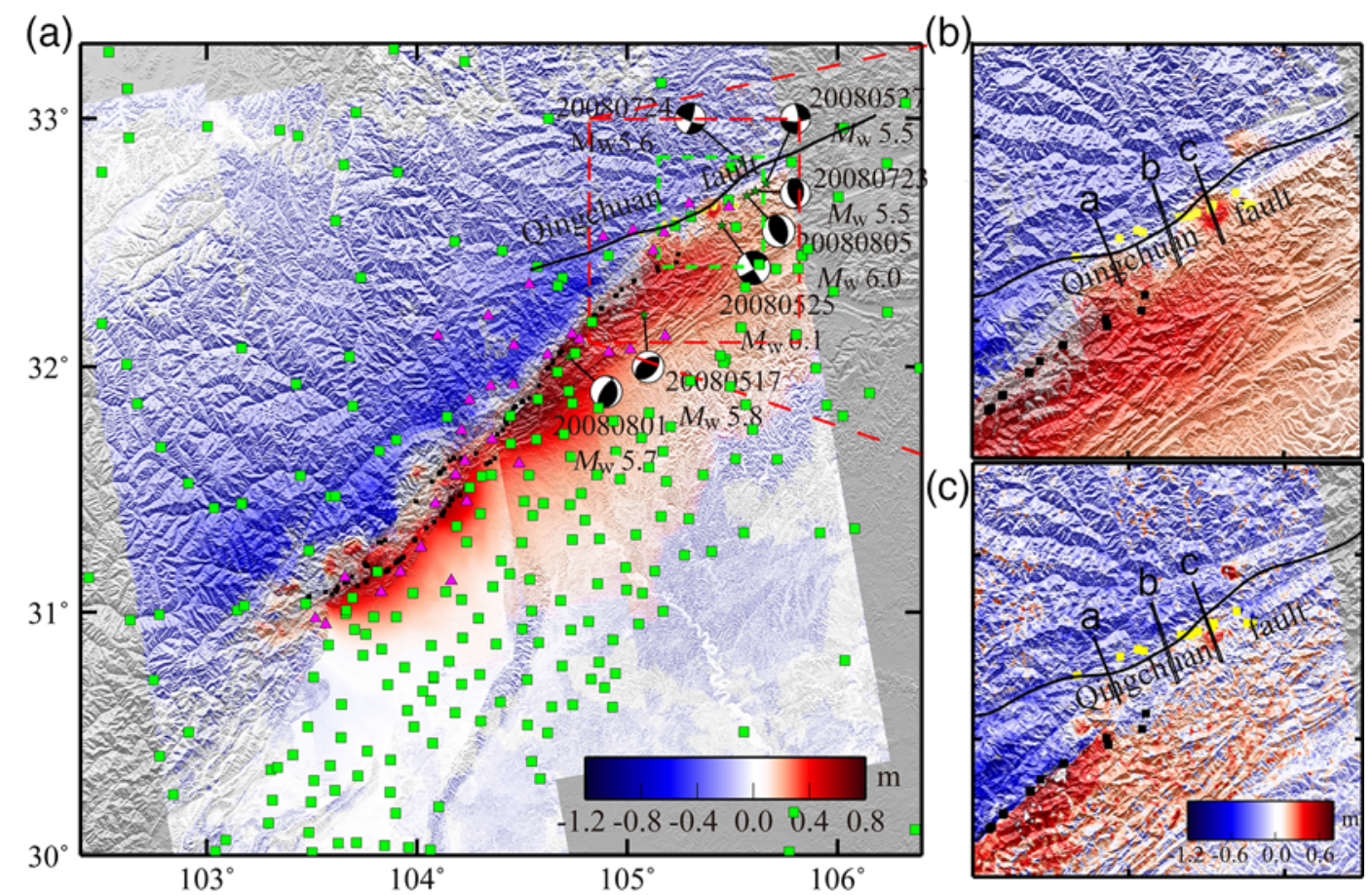

Figure 12. Unwrapped coseismic displacements from the ascending ALOS data with locations of the GPS sites (squares) and the 33 triangulation sites (triangles) that were resurveyed by GPS after the earthquake. Seven aftershocks (magnitude $>5.5$ ) are also shown. The points mark measurement locations in Lin et al. (2012). The (b) InSAR and (c) range-offset displacements within the big dashed rectangle are shown. Profiles a, b, and c are shown in Figure 13. The small dashed rectangle shows the coverage in Figure 14. The color version of this figure is available only in the electronic edition.

A right-lateral and vertical movement along this fault, which strikes $\mathrm{N} 70^{\circ} \mathrm{E}$, should be clearly detectable in our ascending ALOS dataset. However, no discontinuities are visible in the unwrapped InSAR observations or in the offset measurements (see Fig. 12b,c) along the Qingchuan fault, contrasting the results of Lin et al. $(2009,2012)$. Displacement profiles across the fault also show that the displacement gradient is smooth from north to south and without discontinuities (Fig. 13).

Although the profiles show no significant offsets across the Qingchuan fault, there is a concentrated LoS displace- ment (about $40 \mathrm{~cm}$ ) in Qingchuan County, shown as concentric fringes (see coseismic interferograms in Figs. 2 and 14). We explore whether this deformation could be related to the largest aftershock of $M_{\mathrm{w}} 6.1$ (25 May 2008) that occurred in this area. Both the U.S. Geological Survey and Global Centroid Moment Tensor reported that the depth of the $M_{\mathrm{w}} 6.1$ aftershock was greater than $18 \mathrm{~km}$, which would have produced surface LoS displacements less than $10 \mathrm{~cm}$, that is, significantly less than what we observed in Figure 14. This indicates that the observed deformation was probably not related to the aftershocks. To study this further, we isolated this 
(a)

(b)

(c)

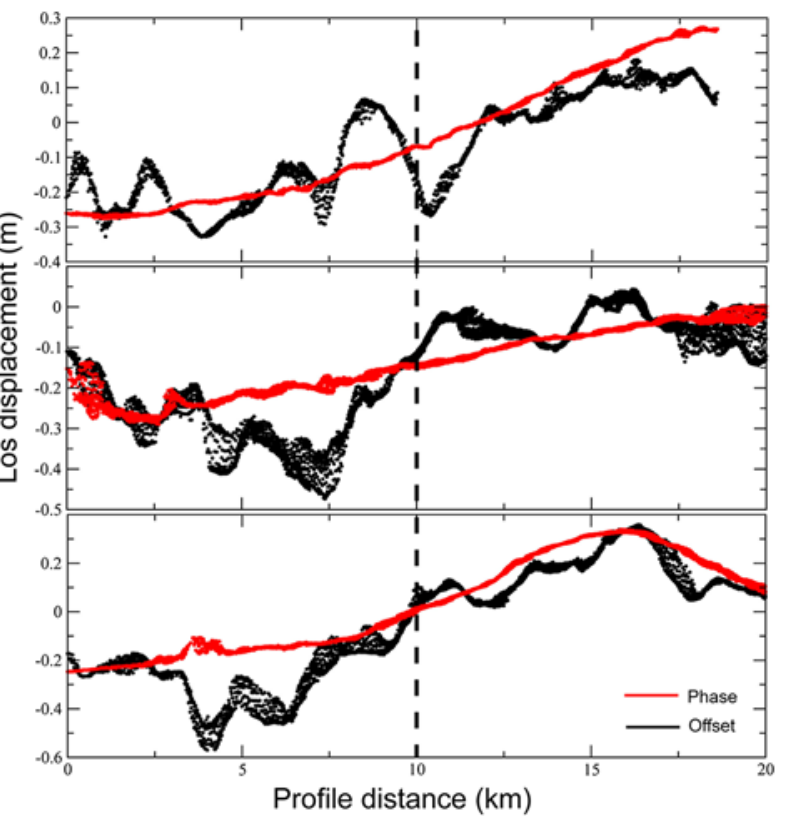

Figure 13. LoS displacement profiles across the Qingchuan fault (for location see Fig. 12) from unwrapped ALOS InSAR observations and range-pixel offsets. The dashed line indicates the location of the surface rupture reported by Lin et al. (2012). The color version of this figure is available only in the electronic edition.

deformation signal by removing the coseismic deformation of the mainshock based on our previously published model (Feng et al., 2010). We then modeled this subevent and estimated its source parameters. Figure 14 shows the observed and predicted deformation, as well as residuals and the estimated fault-slip distribution, extending from the surface down to $10-15 \mathrm{~km}$ depth. We find that this subevent has almost pure thrust faulting on a $60^{\circ}$ northwest dipping fault, centered at a depth of $8 \mathrm{~km}$, and it corresponds to a magnitude $M_{\mathrm{w}}$ 6.6. This moment magnitude is too large to be explained by the aftershocks that occurred in this area, and we therefore conclude that this subevent must be a part of the 2008 Wenchuan mainshock.

The subevent deformation is truncated on the southeastern side of the Beichuan fault, indicating about a 20-km-long northeast-trending surface rupture (see Fig. 14). The fault-slip model reflects this because it has $\sim 60 \mathrm{~cm}$ vertical and $\sim 15 \mathrm{~cm}$ horizontal surface offset. The subevent rupture appears to be located on a northward extension of the Beichuan fault but not on the old Qingchuan fault. However, the northernmost surface rupture of the subevent is close to a few locations marked by Lin et al. (2012) near Guangyuan (Fig. 14), and the subevent rupture may thus in part explain the offsets reported in that study. However, removing the subevent deformation clearly shows that the InSAR observations are smooth across the Qingchuan fault (Fig. 13d), which demonstrates that the Qingchuan fault did not rupture in the 2008 Wenchuan earthquake and that the offsets reported by Lin et al. (2012) are likely older.

\section{Discussion}

Comparison between the InSAR observations and the GPS data shows that the accuracy of our ionospheric-corrected ALOS coseismic deformation is higher than that of previous studies on the 2008 Wenchuan earthquake. The strong ionospheric distortions that are present in the coseismic ALOS data of earlier studies undoubtedly would lead to significant errors and artifacts in estimated fault-slip models of the earthquake, even though the GPS data were also used in the modeling. In addition to the corrected ascending ALOS data, we map the coseismic deformation using descending ALOS ScanSAR and Envisat data. These accurate coseismic InSAR observations could thus provide a good starting point for updated fault-slip modeling efforts in the future.

Some of the GPS stations appear to show anomalous displacement, which is not an uncommon phenomenon in earthquake deformation studies, especially for great subduction and intraplate earthquakes for which the deformation is large and significant strong motions have occurred. For example, several anomalous coseismic GPS station displacements were identified in the $2011 M_{\mathrm{w}} 9.0$ Tohoku-Oki earthquake in Japan (Feng and Jónsson, 2012). The anomalous stations could be detected because they showed significantly different displacement than their neighboring GPS sites. This procedure can be used in cases like the Tohoku-Oki earthquake, in which the deformation field is smooth and GPS stations are abundant. Comparison to InSAR observations can also be used to reveal outlier GPS station displacements. In previous studies on the 2008 Wenchuan earthquake, however, anomalous GPS sites could not be detected because the only independent measurements to compare with the GPS data were the aforementioned ionosphere-disturbed ALOS data. Here, on the other hand, we could identify a few anomalous GPS stations after the comparison with the ionosphere-corrected InSAR data. Fielding et al. (2013) used the predicted ground displacement from their optimal fault model to recognize anomalous GPS stations and also found some anomalous GPS sites.

Both range and azimuth SAR image offsets are usually used to locate surface ruptures in large earthquakes. In previous studies of this earthquake, only the range offsets were used, because the significant ionospheric effects influence the azimuth offsets. However, the range offsets are only sensitive to displacements along the LoS direction, whereas displacements perpendicular to the $\operatorname{LoS}$ are invisible. By adding the ionospheric free-azimuth offsets, we get a more complete picture of the surface ruptures; for example, these data allow us to constrain the location of the fault rupture along the Beichuan and Pengguan faults, between Xiaoyudong and Gaochuan, where large north-south displacements occurred. In total, we show that 240,60 , and $12 \mathrm{~km}$ sections along the Beichuan, Pengguan, and Xiaoyudong faults, respectively, ruptured in the 2008 Wenchuan earthquake. When compared with previous studies that map the fault ruptures using SAR image offsets (Kobayashi et al., 2009; Shen et al., 2009; de 
(a)

(c)

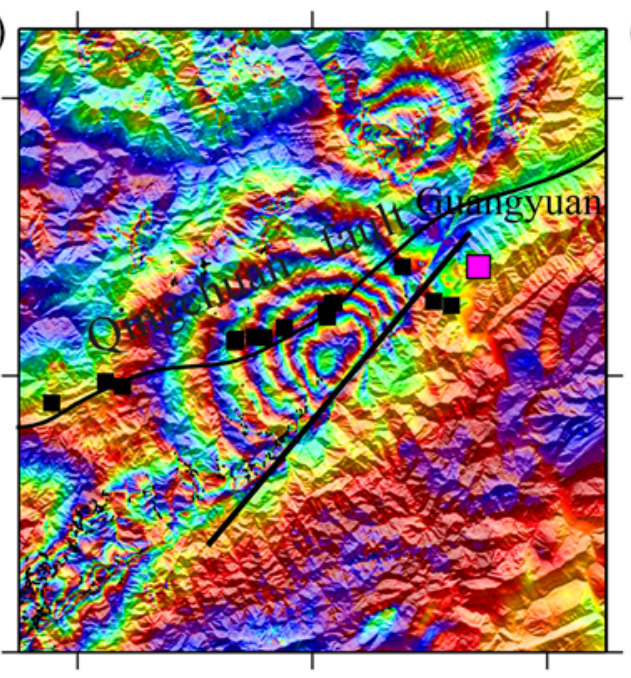

Slip distribution

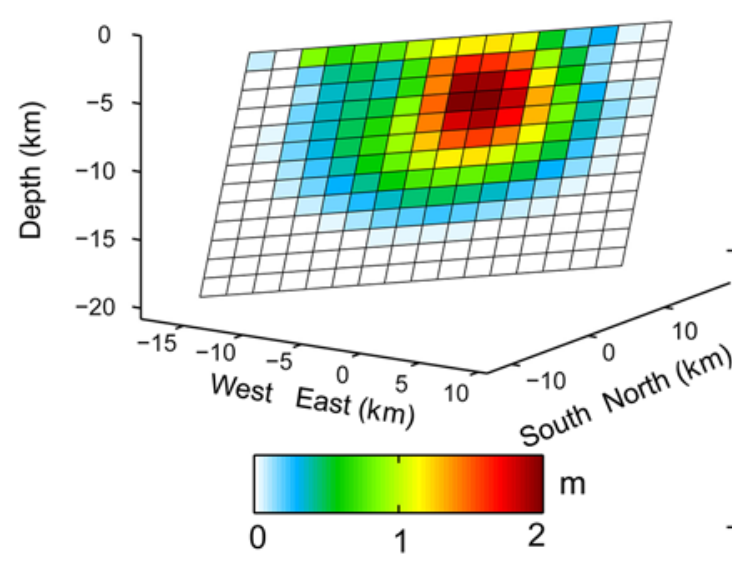

(b)

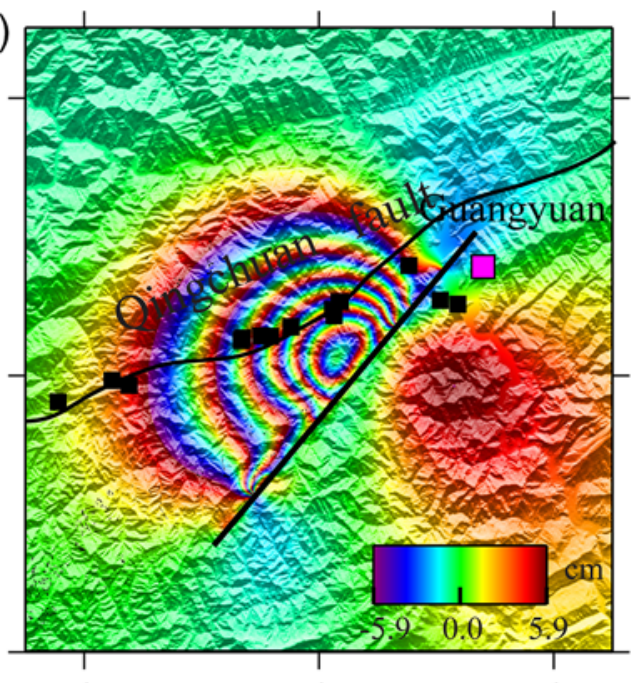

(d)

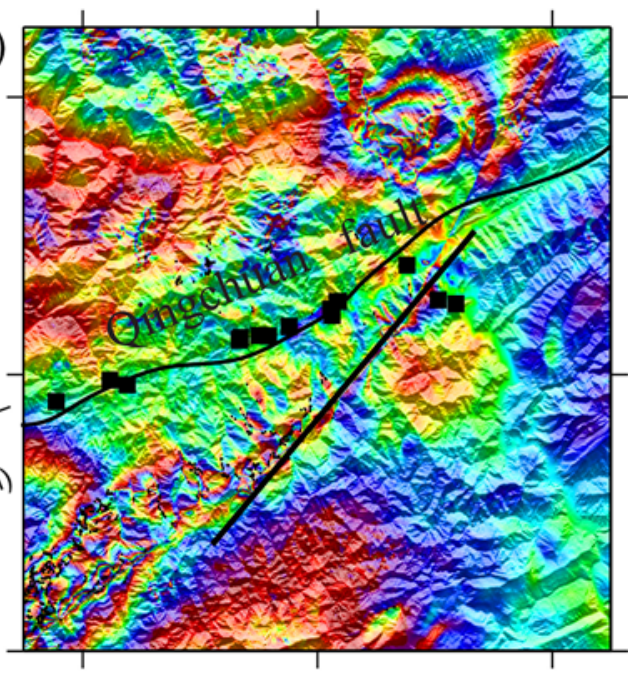

Figure 14. Coseismic deformation and estimated fault slip of a subevent near the northernmost part of the Wenchuan earthquake rupture. The squares mark measurement locations in Lin et al. (2012). (a) Observed coseismic deformation of the subevent in an ascending ALOS interferogram after removing deformation from the Wenchuan mainshock using the fault-slip model of Feng et al. (2010), (b) and (d) predicted and residual subevent deformation based on (c) the model slip distribution. The color version of this figure is available only in the electronic edition.

Michele, Raucoules, de Sigoyer, et al., 2010), our results provide a clearer overall picture of the ruptures and more accurate offset displacements in the fault rupture zone. The improvement is especially great along the Beichuan fault, because the ionospheric effects are particularly dominant in SAR images from paths 472, 473, and 475 (see Fig. 5). Furthermore, the end points of the Wenchuan ruptures can be revised based on our pixel-offset measurements. The results indicate that the southern tip of the Beichuan rupture is well defined at $31.065^{\circ} \mathrm{N}$ and $103.551^{\circ} \mathrm{E}$, whereas its northern end point is less clear. Based on the discontinuities in Figure 5, we estimate that the northern tip of Beichuan rupture is at around $32.424^{\circ} \mathrm{N}$ and $105.126^{\circ} \mathrm{E}$, which is on the northeast of what Li et al. (2010) reported, based on field investigations $\left(32.283^{\circ} \mathrm{N}, 104.933^{\circ} \mathrm{E}\right)$.

Our derived 3D surface measurements (Fig. 6) confirm the locations where maximum fault-rupture offsets were ob- served in the field surveys (i.e., Yingxiu and Beichuan counties for the maximum right-lateral offset along the Beichuan fault; Shaba for the maximum vertical offset along the Pengguan fault). The mapped surface offsets show a vertical movement up to $\sim 6.5 \mathrm{~m}$ accompanied by a dextral peak motion up to $\sim 5.5 \mathrm{~m}$ on the Beichuan fault. The pure thrust faulting on the Pengguan fault is found to have a peak of $\sim 3.5 \mathrm{~m}$. A large vertical offset of up to $\sim 10 \mathrm{~m}$ was reported on the north of the town of Beichuan by Liu-Zeng et al. (2009), though it was later reevaluated by Xu et al. (2009) as a local anomaly because it decreases sharply to 5-6 m within 1-2 km from the maximum. Our offset measurements do not show this anomalous vertical offset, possibly due to the low resolution of the offset measurements (about $1 \mathrm{~km}$ ) and the use of median filtering for reducing noise. In Yingxiu, Beichuan, and Nanba, our results show larger horizontal rupture offsets than the field survey results, with maximum 
offset values reaching $5.5 \mathrm{~m}$ in both Yingxiu and Beichuan. This indicates that the field studies may have underestimated the horizontal rupture offsets in this earthquake.

From previous studies, we know that one of the most noteworthy features of the Wenchuan earthquake is the gradual increase of right-lateral fault slip along the Beichuan fault from Yingxiu to Nanba, whereas reverse slip decreases from southwest to northeast. However, the detailed pattern of the ratio between horizontal and vertical offsets along the Beichuan fault has been difficult to derive due to the sparse field observations along the surface rupture. In this study, we obtained this ratio along the entire Beichuan rupture (Fig. 11) and found that strike slip along the southern part of the Beichuan fault was underestimated in most previous studies.

The use of pixel tracking, either from SAR images or from optical satellite images, became a critical tool to assess surface ruptures of large continental earthquakes (e.g., Peltzer et al., 1999; Binet and Bollinger, 2005; Klinger et al., 2006; Pathier et al., 2006; Vallage et al., 2015). The spatial coverage of satellite images allows encompassing large areas and providing more continuous slip distribution than in most field surveys, which are limited by the availability of recognizable offset landforms. In the case of the 2008 Wenchuan earthquake, in which the rupture propagated through rugged terrains, in some places heavily vegetated, this appears to be crucial to obtain the most complete view of the surface slip distribution. On average, pixel correlation and field measurements agree on the upper values of slip measured at different places along the ground ruptures, though measurements collected in the field tend to underestimate deformation at the surface (Fig. 9). This is partly due to the difficulty in recognizing offset features in the field and to the fact that, most often, the initial shape of offset features is not known with accuracy (Klinger et al., 2005). Part of the deformation might also be distributed, making it more difficult to quantify offsets in the field, though they can be captured with pixeltracking techniques (Vallage et al., 2015). However, in some cases offsets measured in the field are much larger than those obtained by pixel-tracking techniques, as illustrated along the Pengguan section of the rupture (Fig. 10). We suggest that this is in large part due to the difficulty in differentiating cumulative offset associated with several earthquakes from the last coseismic offset, especially when one deals with natural geomorphological landforms (Klinger et al., 2005). The main limitation, so far, of pixel-tracking techniques has been the low resolution of the displacement maps, which is inherent to the fact of forming correlation windows of several tens of pixels. However, the emergence of new sensors, both optical and radar sensors, with higher nominal resolution, in parallel with development of new correlation methodology (Rosu et al., 2014), are quickly overcoming this limitation and allow for laterally denser slip distribution to document slip variations at higher spatial frequencies (Rockwell et al., 2002; Rockwell and Klinger, 2013; Vallage et al., 2015), a key parameter to better understand earthquake rupture processes.

\section{Conclusions}

We presented the most complete displacement field of the 2008 Wenchuan earthquake to date using InSAR datasets from the ALOS and Envisat satellites. Comparisons with GPS data and field observations show that our results are more accurate than the InSAR observations presented in earlier studies, which were strongly contaminated by ionospheric disturbances. We have also derived the complete 3D surface displacement field from SAR image offsets and provided unprecedented details of the near-fault displacements. From these results, we find large right-lateral strike-slip displacements along the southern Beichuan fault (Yingxiu County) that were underestimated in previous studies. We also find that the Qingchuan fault did not rupture in the 2008 Wenchuan earthquake, in contrast to some of the field observation reports. Close to the Qingchuan fault, however, we find a local fault offset caused by an $M_{\mathrm{w}} 6.6$ subevent on a northwest-dipping thrust fault. This subevent occurred on a northward extension of the Beichuan fault and appeared to have been a part of the mainshock.

\section{Data and Resources}

The Global Centroid Moment Tensor (Global CMT) Project database was searched using www.globalcmt.org/ CMTsearch.html (last accessed April 2014). The U.S. Geological Survey (USGS) aftershock database was searched using http://earthquake.usgs.gov/earthquakes/map/ (last accessed April 2014).

\section{Acknowledgments}

The authors would like to thank Associate Editor Bill Hammond and two anonymous reviewers for critical comments and suggestions. The Advanced Land Observing Satellite (ALOS) data were provided by the Japan Aerospace Exploration Agency (JAXA) through projects P1229002 and P1390002, and the Envisat data were obtained through the GEO Geohazards Supersites project (C1P.14838 and C1P.16734). Figures were prepared using the Generic Mapping Tools (GMT) software (Wessel and Smith, 1998). The research was supported by King Abdullah University of Science and Technology (KAUST).

\section{References}

Binet, R., and L. Bollinger (2005). Horizontal coseismic deformation of the 2003 Bam (Iran) earthquake measured from SPOT-5 THR satellite imagery, Geophys. Res. Lett., 32, no. 2, doi: 10.1029/2004GL021897.

Chapin, E., S. F. Chan, B. D. Chapman, C. W. Chen, and J. M. Martin (2006). Impact of the ionosphere on an L-band space based radar, Proc. of IGARSS 2006, 6th European Conf. on Synthetic Aperture Radar (EUSAR), Dresden, Germany, 17 May, 51-58.

Chen, C. W., and H. A. Zebker (2001). Two-dimensional phase unwrapping with use of statistical models for cost functions in nonlinear optimization, J. Opt. Soc. Am. A. 18, no. 3, 338-351.

de Michele, M., D. Raucoules, J. de Sigoyer, M. Pubellier, and N. ChamotRooke (2010). Three-dimensional surface displacement of the 2008 May 12 Sichuan earthquake (China) derived from Synthetic Aperture Radar: Evidence for rupture on a blind thrust, Geophys. J. Int. 183, 1097-1103. 
de Michele, M., D. Raucoules, C. Lasserre, E. Pathier, Y. Klinger, J. van der Woerd, J. de Sigoyer, and X. Xu (2010). The $M_{\mathrm{w}}$ 7.9, 12 May 2008 Sichuan earthquake rupture measured by sub-pixel correlation of ALOS PALSAR amplitude images, Earth Planets Space 62, 875-879, doi: 10.5047/eps.2009.05.002.

Feng, G. (2011). Coseismic deformation and ionospheric variation associated with the Wenchuan earthquake estimated from InSAR, Ph.D. Thesis, The Hong Kong Polytechnic University, Hong Kong, China, 145 pp.

Feng, G., and S. Jónsson (2012). Shortcoming of InSAR for studying megathrust earthquakes: The case of the $M_{\mathrm{w}} 9.0$ Tohoku-Oki earthquake, Geophys. Res. Lett. 39, L10305, doi: 10.1029/2012GL051628.

Feng, G., E. A. Hetland, X. Ding, Z. Li, and L. Zhang (2010). Coseismic fault slip of the $2008 M_{\mathrm{w}} 7.9$ Wenchuan earthquake estimated from InSAR and GPS measurements, Geophys. Res. Lett. 37, L01302, doi: 10.1029/2009GL041213.

Feng, G., Z. Li, X. Shan, L. Zhang, G. Zhang, and J. Zhu (2015). Geodetic model of the April 25, $2015 M_{\mathrm{w}} 7.8$ Gorkha Nepal earthquake and $M_{\mathrm{w}} 7.3$ aftershock estimated from InSAR and GPS data, Geophys. J. Int. 203, no. 2, 896-900, doi: 10.1093/gji/ggv335.

Feng, G., L. Zhiwei, S. Xinjian, X. Bing, and D. Yanan (2015). Source parameters of the $2014 M_{\mathrm{w}}$ 6.1 South Napa earthquake estimated from the Sentinel 1A, COSMO-SkyMed and GPS data, Tectonophysics 655, 139-146, doi: 10.1016/j.tecto.2015.05.018.

Fielding, E. J., A. Sladen, Z. Li, J.-P. Avouac, R. Bürgmann, and I. Ryder (2013). Kinematic fault slip evolution source models of the 2008 M7.9 Wenchuan earthquake in China from SAR interferometry, GPS, and teleseismic analysis and implications for Longmen Shan tectonics, Geophys. J. Int. 194, no. 2, 1138-1166, doi: 10.1093/ gji/ggt155.

Furuya, M., T. Kobayashi, Y. Takada, and M. Murakami (2010). Fault source modeling of the 2008 Wenchuan earthquake based on ALOS/PALSAR data, Bull. Seismol. Soc. Am. 100, 2750-2766.

Hao, K. X., H. Si, H. Fujiwara, and T. Ozawa (2009). Coseismic surfaceruptures and crustal deformations of the 2008 Wenchuan earthquake $M_{\mathrm{w}}$ 7.9, China, Geophys. Res. Lett. 36, L11303, doi: 10.1029/ 2009GL037971.

Hashimoto, M., E. Mari, and F. Yo (2010). Coseismic deformation from the 2008 Wenchuan, China, earthquake derived from ALOS/PALSAR images, Tectonophysics 491, 59-71, doi: 10.1016/j.tecto.2009.08.034.

Huang, R., and X. Fan (2013). The landslide story, Nature Geosci. 6, no. 5, 325-326, doi: 10.1038/ngeo1806.

Klinger, Y., C. Ji, Z.-K. Shen, and W. H. Bakun (2010). Introduction to the special issue on the 2008 Wenchuan, China, earthquake, Bull. Seismol. Soc. Am. 100, 2353-2356.

Klinger, Y., R. Michel, and G. C. P. King (2006). Evidence for an earthquake barrier model from $M_{\mathrm{w}}$ similar to 7.8 Kokoxili (Tibet) earthquake slipdistribution, Earth Planet. Sci. Lett. 242, nos. 3/4, 354-364.

Klinger, Y., X. W. Xu, P. Tapponnier, J. Van der Woerd, C. Lasserre, and G. King (2005). High-resolution satellite imagery mapping of the surface rupture and slip distribution of the $M_{\mathrm{w}} 7.8,14$ November 2001 Kokoxili earthquake, Kunlun fault, northern Tibet, China, Bull. Seismol. Soc. Am. 95, no. 5, 1970-1987.

Kobayashi, T., Y. Takada, M. Furuya, and M. Murakami (2009). Locations and types of ruptures involved in the 2008 Sichuan earthquake inferred from SAR image matching, Geophys. Res. Lett. 36, L07302, doi: 10.1029/2008GL036907.

Kurahashi, S., and K. Irikura (2010). Characterized source model for simulating strong ground motions during the 2008 Wenchuan earthquake, Bull. Seismol. Soc. Am. 100, 2450-2475.

Li, C.-Y., Z.-Y. Wei, J.-Q. Ye, Y.-B. Han, and W.-J. Zheng (2010). Amounts and styles of coseismic deformation along the northern segment of surface rupture of the 2008 Wenchuan $M_{\mathrm{w}} 7.9$ earthquake, China, Tectonophysics 491, nos. 1/4, 35-58.

Li, Z. W., X. L. Ding, C. Huang, J. J. Zhu, and Y. L. Chen (2008). Improved filtering parameter determination for the Goldstein radar interferogram filter, Photogramm. Remote Sens. 63, no. 6, 621-634.
Lin, A., G. Rao, and B. Yan (2012). Field evidence of rupture of the Qingchuan fault during the $2008 M_{\mathrm{w}} 7.9$ Wenchuan earthquake, northeastern segment of the Longmen Shan thrust belt, China, Tectonophysics 522/ 523, 243-252, doi: 10.1016/j.tecto.2011.12.012.

Lin, A., Z. Ren, D. Jia, and X. Wu (2009). Co-seismic thrusting rupture and slip distribution produced by the $2008 M_{\mathrm{w}} 7.9$ Wenchuan earthquake, China, Tectonophysics 471, nos. 3/4, 203-215.

Liu-Zeng, J., Z. Zhang, L. Wen, P. Tapponnier, J. Sun, X. Xing, G. Hu, Q. Xu, L. Zeng, L. Ding, et al. (2009). Co-seismic ruptures of the 12 May 2008, $M_{\mathrm{s}}$ 8.0 Wenchuan earthquake, Sichuan: East-west crustal shortening on oblique, parallel thrusts along the eastern edge of Tibet, Earth Planet. Sci. Lett. 286, nos. 3/4, 355-370, doi: 10.1016/j.eps1.2009.07.017.

Michel, R., J.-P. Avouac, and J. Taboury (1999). Measuring ground displacements from SAR amplitude images: Application to the Landers earthquake, Geophys. Res. Lett. 26, no. 7, 875-878.

Pathier, E., E. Fielding, T. Wright, R. Walker, B. Parsons, and S. Hensley (2006). Displacement field and slip distribution of the 2005 Kashmir earthquake from SAR imagery, Geophys. Res. Lett. 33, L20310, doi: 10.1029/2006GL027193.

Peltzer, G., F. Crampe, and G. King (1999). Evidence of nonlinear elasticity of the crust from the $M_{\mathrm{w}}$ 7.6 Manyi (Tibet) earthquake, Science 286, 272-276.

Raucoules, D., and M. de Michele (2010). Assessing ionospheric influence on L-band SAR data: Implications on co-seismic displacement measurements of the 2008 Sichuan earthquake, IEEE Geosci. Remote Sens. Lett. 7, no. 2, 286-290, doi: 10.1109/LGRS.2009.2033317.

Rockwell, T. K., and Y. Klinger (2013). Surface rupture and slip distribution of the 1940 Imperial Valley earthquake, Imperial fault, southern California: Implications for rupture segmentation and dynamics, Bull. Seismol. Soc. Am. 103, no. 2A, 629-640.

Rockwell, T. K., S. Lindvall, T. Dawson, R. Langridge, W. Lettis, and Y. Klinger (2002). Lateral offsets on surveyed cultural features resulting from the 1999 Izmit and Duzce earthquakes, Turkey, Bull. Seismol. Soc. Am. 92, 79-94.

Rosu, A. M., M. Pierro-Deseilligny, A. Delorme, A. Binet, and Y. Klinger (2014). Measurement of ground displacement from optical satellite image correlation using the free open-source software MicMac, ISPRS J. Photogramm. Remote Sens. 100, 48-59, doi: 10.1016/j.isprsjprs.2014.03.002.

Shen, Z. K, J. B Sun, P. Z. Zhang, Y. G. Wan, M. Wang, R. Bürgmann, Y. H. Zeng, W. J. Gan, H. Liao, and Q. L. Wang (2009). Slip maxima at fault junctions and rupturing of barriers during the 2008 Wenchuan earthquake, Nature Geosci. 2, 718-724.

Strozzi, T., A. Luckman, T. Murray, U. Wegmuller, and C. Werner (2002). Glacier motion estimation using SAR offset-tracking procedures, IEEE Trans. Geosci. Remote Sens. 40, no. 11, 2384-2391.

Tong, X., D. T. Sandwell, and Y. Fialko (2010). Coseismic slip model of the 2008 Wenchuan earthquake derived from joint inversion of interferometric synthetic aperture radar, GPS, and field data, J. Geophys. Res. 115, no. B04314, doi: 10.1029/2009JB006625.

Vallage, A., Y. Klinger, R. Grandin, H. S. Bhat, and M. Pierrot-Deseilligny (2015). Inelastic surface deformation during the $2013 M_{\mathrm{w}} 7.7$ Balochistan, Pakistan, earthquake, Geology 43, no. 12, 1079-1082, doi: 10.1130/G37290.1.

Wang, Q., X. Qiao, Q. Lan, J. T. Freymueller, S. Yang, C. Xu, Y. Yang, X. You, K. Tan, and Q. Shen (2011). Rupture of deep faults in the 2008 Wenchuan earthquake and uplift of the Longmen Shan, Nature Geosci. 4, 634-640, doi: 10.1038/ngeo1210.

Wang, T., and S. Jónsson (2015). Improved SAR amplitude image offset measurements for deriving three-dimensional coseismic displacements, IEEE J. Sel. Top. Appl. Remote Sens. 8, no. 7, 3271-3278, doi: 10.1109/JSTARS.2014.2387865.

Wegmüller, U., and C. L. Werner (1997). Gamma SAR processor and interferometry software, Proc. of the 3rd ERS Symposium, Eur. Space Agency Spec. Publ., ESA SP-414, 1686-1692.

Wegmüller, U., C. L. Werner, T. Strozzi, and A. Wiesmann (2006). Ionospheric electron concentration effects on SAR and InSAR, Proc. of IGARSS 2006, Denver, Colorado, 31 July-4 August, 3714-3717. 
Werner, C., U. Wegmuller, T. Strozzi, and A. Wiesmann (2005). Precision estimation of local offsets between SAR SLCs and detected SAR images, Proc. of IGARSS 2005, Seoul, Korea, 25-29 July, 4803-4805.

Wessel, P., and W. H. F. Smith (1998). New, improved version of the Generic Mapping Tools released, Eos Trans. $A G U$ 79, no. 47, 579.

Xu, X. W., X. Wen, G. Yu, G. Chen, Y. Klinger, J. Hubbard, and J. Shaw (2009) Co-seismic reverse- and oblique-slip surface faulting generated by the $2008 M_{\mathrm{w}} 7.9$ Wenchuan earthquake, China, Geology 37, no. 6, 515-518.

Yin, A. (2010). A special issue on the great 12 May 2008 Wenchuan earthquake $\left(M_{\mathrm{w}} 7.9\right)$ : Observations and unanswered questions, Tectonophysics 491, 1-9.

Zhang, G., M. Vallée, X. Shan, and B. Delouis (2012). Evidence of sudden rupture of a large asperity during the $2008 M_{\mathrm{w}} 7.9$ Wenchuan earthquake based on strong motion analysis, Geophys. Res. Lett. 39, L17303, doi: 10.1029/2012GL052516.

Zhang, P. Z., X. Z. Wen, Z. K. Shen, and J. H. Chen (2010). Oblique, high-angle, listric-reverse faulting and associated development of strain: The Wenchuan earthquake of May 12, 2008, Sichuan, China,
Annu. Rev. Earth Planet. Sci. 38, 353-382, doi: 10.1146/annurev-earth040809-152602.

King Abdullah University of Science and Technology (KAUST)

Thuwal 23955, Saudi Arabia

(G.F., S.J.)

Institut de Physique du Globe de Paris

CNRS, UMR 7153

France

(Y.K.)

Manuscript received 22 April 2016;

Published Online 14 March 2017 